\title{
LA GESTIÓN DE LOS RESIDUOS SÓLIDOS URBANOS Y LA SALUD: APORTES DESDE EL DERECHO AMBIENTAL
}

\section{THE MANAGEMENT OF URBAN SOLID WASTE AND HEALTH: CONTRIBUTIONS FROM ENVIRONMENTAL LAW}

\section{María Laura Foradori ${ }^{1}$}

DOI: https://doi.org/10.37767/2591-3476(2020)34

\section{Comentario a}

Complejo Ambiental de Tratamiento, Valorización y Disposición Final

de Residuos Sólidos Urbanos de Córdoba

\section{Cámara Contencioso-Administrativa de 1ra Nominación}

(Poder Judicial de la Provincia de Córdoba)

\author{
Disponible en \\ https://bit.ly/2ClcDNJ
}

\section{RESUMEN:}

Este trabajo tiene por objetivo comentar la sentencia en los autos caratulados: “Complejo Ambiental de Tratamiento, Valoración y Disposición Final de Residuos Sólidos Urbanos de Córdoba y otros - Cuestión Ambiental" de la Cámara Contencioso Administrativa de $1^{\circ}$ Nominación de la Provincia de Córdoba. El Tribunal, en dicho decisorio de diciembre de 2019, niega la instalación del "Complejo Ambiental" para la disposición final de los residuos de la ciudad de Córdoba y otros municipios y comunas, en el sito seleccionado por CORMECOR (Corporación Intercomunal para la Gestión Sustentable de los Residuos Sólidos Urbanos del Área Metropolitana de Córdoba).

Los principales fundamentos del Tribunal para así decidir fueron: que no se respeta la distancia entre el predio para el enterramiento y el borde urbano de Villa Parque Santa Ana, conforme recomiendan estudios técnicos confirmados por las pericias oficiales; que no se llevó a cabo de manera adecuada el proceso de Evaluación de Impacto Ambiental y su audiencia pública, como establece la ley de Política Ambiental Provincial №10208.

Este fallo nos invita a reflexionar en torno a dos derechos humanos íntimamente relacionados: el derecho a la salud y el derecho a un ambiente sano. Con el foco en éste vínculo, y desde una perspectiva ambiental, se repasarán los puntos centrales del caso, exponiendo cuestiones conceptuales y normativas.

\footnotetext{
1 Abogada (UNC); Diplomada en Política Ambiental de Córdoba e instrumentos de gestión (UTN-Villa María); Especialista en Educación Ambiental (UNINI); Doctoranda en Ciencia Política (CEA-UNC). Docente e Investigadora de la Facultad de Derecho de la Universidad Nacional de Córdoba, Facultad de Derecho y Ciencias Sociales de la Universidad Católica de Córdoba, Universidad Nacional de Villa María y Universidad Siglo 21. Mail: mlauraforadori@gmail.com. Nro. de ORCID: https://orcid.org/0000-0001-8666-7647
} 


\begin{abstract}
The objective of this work is to comment on the judgment in the proceedings entitled: "Environmental Complex for Treatment, Assessment and Final Disposal of Urban Solid Waste of Córdoba and others - Environmental Issue" of the Administrative Litigation Chamber of 1st Nomination of the Province of Córdoba. This Court, in said decision of December 2019, denies the installation of the "Environmental Complex" for the final disposal of waste from the city of Córdoba and other municipalities and communes, at the site selected by CORMECOR (Intercommunal Corporation for Sustainable Management Solid Urban Waste of the Córdoba Metropolitan Area).

The main grounds for the Court to decide this were: that the distance between the burial site and the urban edge of Villa Parque Santa Ana is not respected, as recommended by technical studies confirmed by official expertise; that the Environmental Impact Assessment process and its public hearing were not adequately carried out, as established by the Provincial Environmental Policy Law $\mathrm{N}^{\circ} 10208$.

This ruling invites us to reflect on two closely related human rights: the right to health and the right to a healthy environment. With the focus on this link, and from an environmental perspective, the central points of the case will be reviewed, exposing conceptual and normative issues.
\end{abstract}

PALABRAS CLAVE: derecho ambiental; derecho a la salud; residuos sólidos urbanos; Complejo Ambiental; evaluación de impacto ambiental.

KEY WORDS: environmental law; right to health; urban solid waste; Environmental Complex; environmental impact assessment.

\title{
I. Introducción
}

Los residuos sólidos urbanos, particularmente su gestión, presentan riesgos para el ambiente y la salud colectiva. A pesar de ello no hay acciones tendientes a mejorar realmente su gestión en América Latina, y particularmente en Argentina (Pascual et al., 2010). El conflicto sociambiental en torno a la basura y la gestión de los residuos sólidos urbanos es de larga data, y puede ser analizado desde diferentes dimensiones, desde la social, política, cultural, hasta la económica y jurídica. En este comentario a fallo se hará hincapié en la última, y particularmente se abordará desde el derecho ambiental, considerándolo en estrecha relación con el derecho a la salud.

Tanto el derecho a gozar de un ambiente sano como el derecho a la salud son derechos humanos y de incidencia colectiva (Iglesias Rossini, 2016). En este sentido, Cafferatta sostiene que "en la mayoría de los casos se protege al medio ambiente y la salud, no ya como derechos subjetivos individuales, de cada persona, exclusivos propios, diferenciados, o fragmentarios, sino como bienes colectivos y hasta difusos o, públicos, generales o supraindividuales" (Cafferatta, 2011: 651).

A partir de ese marco, en esta nota, el fallo que se aborda es la sentencia de la Cámara Contencioso Administrativa de $1^{\circ}$ Nominación de la Provincia de Córdoba en la causa caratulada "Complejo Ambiental de Tratamiento, Valoración y Disposición Final de Residuos Sólidos Urbanos de Córdoba y otros - Cuestión Ambiental" del 30 de diciembre de $2019^{2}$. 
El conflicto se presenta en torno a la instalación de una planta de tratamiento de residuos sólidos urbanos (en adelante RSU) en un predio ubicado en cercanías de Villa Parque Santa Ana, a $15 \mathrm{~km}$ al suroeste de la ciudad de Córdoba, departamento Santa María. Como surge de la sentencia, la causa es el resultado de la fusión de varios juicios iniciados por diversos actores, en relación a la ubicación de dicha planta de tratamiento y disposición de los RSU producidos por la Ciudad de Córdoba y otros municipios y comunas que integran la Corporación Intercomunal para la Gestión Sustentable de los Residuos Sólidos Urbanos del Área Metropolitana de Córdoba (en adelante CORMECOR).

El Tribunal, principalmente en base a la pericia técnica multidisciplinaria, de manera unánime hizo lugar a la acción de amparo ambiental y declaró que el sitio seleccionado para la instalación del "Complejo Ambiental de Tratamiento, Valorización y Disposición Final de Residuos Sólidos Urbanos del Área Metropolitana de Córdoba" (en adelante CTVyD) no cumple con los requisitos socio-ambientales establecidos en los Informes realizados por el Instituto Superior de Estudios Ambientales (ISEA) de la Universidad Nacional de Córdoba (UNC).

Entre las razones que llevaron al Tribunal a resolver como lo hizo, se destaca que el emplazamiento en el lugar elegido no expresa fundamentos suficientes para apartarse de las recomendaciones del ISEA, respecto a la distancia mínima que debe separar el emprendimiento del borde urbano más cercano, en este caso, el de Villa Parque Santa Ana. Además, la Cámara sostiene que, en la elección del sitio no se tuvo en cuenta las implicancias sociales que sobre esa misma población tendría la ubicación de un emprendimiento de las características del previsto.

De lo anterior surge la centralidad que se le otorga al "Estudio de sitios" realizado por el ISEA-UNC, considerándolo criterio legítimo para la evaluación del Estudio de Impacto Ambiental (en adelante EsIA) presentado por CORMECOR (realizado por Geoambiental), y aprobado por la Secretaría de Ambiente en 2015 (con condicionantes) y 2017 de manera definitiva.

Para el análisis del caso, se iniciará comentando con mayor detalle los hechos de causa, la historia procesal y los principales ejes de la decisión del Tribunal. Luego, se hará hincapié en la íntima relación entre el derecho a la salud y el derecho a un ambiente sano como derechos humanos, la Evaluación de Impacto Ambiental (en adelante EIA) y la importancia de la participación ciudadana, para finalizar mostrando el marco normativo que rige la gestión de los RSU, particularmente la etapa de disposición final.

\section{Hechos de la causa: historia procesal y decisión del tribunal}

CORMECOR es una Sociedad Anónima constituida en el año 2013; integrada por la Municipalidad de Córdoba (principal accionista), los municipios de Villa Allende, Estación Juárez Celman, Malvinas Argentinas, Río Ceballos, La Calera, Despeñaderos, Alta Gracia, las comunas de Villa La Bolsa y Villa Los Aromos, y el Sindicato Único de Recolección de Residuos y Barridos de Córdoba (SURRBAC).

Conforme surge de su página oficial ${ }^{3}$, en junio del año 2012, antes de su constitución, se firmó un convenio entre la Provincia de Córdoba, la Municipalidad de Córdoba y los Mu- 
nicipios y Comunas del Gran Córdoba con el principal objetivo de trabajar conjuntamente en el tratamiento y disposición final de los RSU producidos en la ciudad de Córdoba y el área metropolitana. Ese mismo año, a través de un convenio firmado con la UNC, se encarga al ISEA la realización de estudios de sitios posibles para el emplazamiento del CTVyD. En dicho estudio, el ISEA, sobre un radio de $50 \mathrm{~km}$ en torno al centro de la ciudad de Córdoba, identifica "zonas aptas" para instalar el enterramiento sanitario en cuestión.

En el año 2015, la Consultora Geoambiental da comienzo al EsIA, determinando como sitio para el enterramiento sanitario un predio cercano a Villa Parque Santa Ana, ubicado en zona rural dentro del Departamento Santa María de la Provincia de Córdoba, entre la Ruta Nacional N 36 y la Ruta Provincial N 5, a una distancia de 15 Kilómetros al Sudoeste de la ciudad de Córdoba. Este EsIA fue aprobado por la Comisión Técnica Interdisciplinaria (en adelante CTI) del, en su momento, Ministerio de Agua, Ambiente y Servicios Públicos de la Provincia de Córdoba. Luego de llevada a cabo una audiencia pública muy controvertida, se otorga Licencia Ambiental con condicionantes (Res. N510/15). Finalmente, en el año 2017, se emite la Licencia Ambiental a través de la Resolución № 10, al haber completado CORMECOR todos los requerimientos indicados en la Resolución anterior, conforme surge del documento.

Al EsIA lo realizó la consultora privada Geoambiental, determinando el predio cercano a Villa Parque Santa Ana como de "muy buena aptitud" para el emplazamiento del CTVyD. Los peritos oficiales confirmaron, en su estudio, que la consultora se apartó de una de las principales recomendaciones del ISEA-UNC en relación a las distancias entre el predio y las poblaciones: $2 \mathrm{~km}$ de zona de exclusión, más $2 \mathrm{~km}$ de buffer o zona de amortiguación. Cabe agregar que, dicho lugar había sido demarcado por el ISEA como zona "apta con condicionantes", y los peritos oficiales al re-evaluar las condiciones del predio utilizando los criterios indicados por el ISEA, lo calificaron como "inaceptable".

Respecto a las diferentes causas unificadas, la primera se presentó en 2014 por la familia Gremo, productores rurales que viven en el paraje Alto El Durazno; y en 2015 la Municipalidad de Villa Parque Santa Ana presentó un amparo en representación de su población. En el año 2016 el conflicto "contra el basural" (Lacombe, 2020) se agudizó al movilizarse y protestar masivamente la comunidad de Villa Parque Santa Ana, lo que llevó a un amparo ambiental colectivo contra CORMECOR. También se unifica la acción declarativa de certeza interpuesta por el propietario de un inmueble rural colindante, José Caparroz. Las demandadas son: CORMECOR, la provincia de Córdoba, la Municipalidad de Córdoba, la Municipalidad de Alta Gracia y la Municipalidad de Villa Allende. Entre otros aspectos, se cuestionan las irregularidades que se presentaron en el proceso de EIA, particularmente respecto a la participación ciudadana, y la ubicación de predio.

A partir de lo anterior, los puntos centrales del debate técnico-jurídico estuvieron dados por: la proximidad del predio elegido por CORMECOR para el enterramiento respecto de la población, la falta de información y participación de los ciudadanos en el proceso de EIA y la magnitud de los daños sociales que no se contemplan en el EsIA presentado por CORMECOR.

Respecto a la ubicación del predio seleccionado, las pericias oficiales confirmaron lo denunciado por los vecinos, que entre el predio elegido por CORMECOR y el ejido de Villa Parque Santa Ana, hay sólo $1 \mathrm{~km}$ de distancia, y no $5 \mathrm{~km}$ como se afirma en el EsIA. Ade- 
más, otras poblaciones afectadas por quedar dentro de la zona de impacto directo -un radio de 4km- serían Bouwer, Los Cedros y los parajes habitados Alto El Durazno y Potrero del Estado. El informe interdisciplinario oficial señaló que la distancia entre el predio y las poblaciones no garantiza la no afectación de la calidad de vida de las poblaciones cercanas, por diversos peligros -principalmente respecto a emisiones gaseosas y malos olores-y sostuvo que no se dan los fundamentos científicos suficientes para apartarse de la recomendación del ISEA respecto a la distancia del borde urbano, el uso del suelo y aspectos sociales vinculados a las características y dimensiones del mega-enterramientos proyectado por CORMECOR.

Respecto a la participación ciudadana; como señalamos en la introducción, el EsIA presentado por CORMECOR, en octubre del año 2015 fue aprobado por la CTl; a partir de lo cual la Secretaría de Ambiente de la Provincia de Córdoba le otorgó licencia ambiental con condicionantes (Res. N510/15); y luego, en 2017, mediante Res. № 10/17, le otorgó a CORMECOR licencia ambiental definitiva, dando por cumplimentados los requisitos/ condiciones indicados en la resolución anterior.

En ese proceso, si bien se llevó a cabo una audiencia pública, hay varias objeciones por parte de los distintos actores. Concretamente, en la sentencia, los camaristas señalan que la CTI al evaluar el EsIA no tuvo en cuenta las opiniones vertidas en la audiencia pública, porque no respondió de manera fundada a las objeciones allí expresadas, tal como exige el artículo 29 de la Ley General del Ambiente Nㅜ25675. Conforme a dicho artículo, si bien lo que surge de la audiencia pública no es vinculante, obliga a los funcionarios a responder de manera fundada a las objeciones planteadas por los participantes. Esto se pone de resalto en la sentencia, que reafirma el valor de la participación ciudadana en los proceso de EIA.

Los camaristas señalaron que la regularidad de la Res. $N^{\circ} 10 / 17$, por la cual se aprueba la licencia ambiental, se ve afectada por no contener una exposición fundada de los motivos del apartamiento de los argumentos expuestos en la audiencia pública, y carecer, de esta manera, de un requisito indispensable impuesto por el ordenamiento vigente en la materia. La Cámara considero que esto invisibilizó a los afectados directos por el emprendimiento Complejo Ambiental, constituyendo el eje central de esas objeciones no respondidas la cuestión de la distancia entre el enterramiento sanitario y las zonas urbanas, afectando de esta manera la calidad de vida de las poblaciones.

En lo que refiere a los aspectos sociales que deben tenerse en cuenta en el proceso de otorgamiento de la licencia ambiental; hubo falencias en su consideración y ponderación a lo largo del proceso administrativo, cuestiones que no se presentaron como autoevidentes; sino que fueron visibilizadas por los actores, para luego, ser evaluadas y consideradas por los peritos oficiales y la sentencia de Cámara (Lacombe, 2020). El Tribunal, siguiendo las conclusiones del Cuerpo de Peritos Oficiales (CPO), afirma que: "El estudio de impacto ambiental presentado tiene en general una estructura, contenido y conclusiones que se corresponden con la realidad física y biológica del área a afectar. No obstante se observan falencias respecto a la estimación de los impactos referidos a emisiones gaseosas y malos olores, dada la proximidad de la comunidad más cercana (Villa Parque Santa Ana) y respecto a los impactos sociales que no han sido considerados en particular y específicamente respecto de la población más afectable en los aspectos negativos del proyecto (Villa Parque Santa Ana)." (Cam. Cont. Adm. 1Nom, 2019: 194). 
Esto muestra una subestimación de los aspectos sociales frente a los biológicos en el proceso del estudio y de la evaluación del impacto ambiental del proyecto de CORMECOR. Lo que evidencia "la naturalización de cierta preminencia jerárquica de los habitualmente llamados: aspectos geofísicos ponderados por las ciencias "exactas"; por sobre los aspectos sociales, entendidos como atinentes a las ciencias "blandas" (Lacombe, 2020: 5). Por lo expuesto, y tomando los fundamentos de la pericia oficial, la Cámara, en una sentencia de 267 páginas, hizo lugar al amparo ambiental y declaró que el sitio seleccionado para la instalación del CTVyD no es adecuado por no cumplir con los requisitos socioambientales establecidos por el ISEA-UNC en su estudio.

\section{El derecho humano a un medioambiente sano: la íntima relación entre medio ambiente y salud}

El reconocimiento de la estrecha relación que existe entre los derechos humanos y el medio ambiente, ha adoptado principalmente dos formas: el reconocimiento explícito de un derecho al medio ambiente; y el fortalecimiento de los vínculos entre derechos ya reconocidos, como los derechos a la vida, la integridad personal y la salud, con el medio ambiente (Morales Lamberti, 2015). En este comentario nos interesa particularmente destacar la interdependencia entre los derechos humanos a un ambiente sano, a la vida y la salud, particularmente vulnerables a la degradación del medio ambiente.

La Corte Interamericana de Derechos Humanos (en adelante CIDH), en el año 2017, en una Opinión consultiva solicitada por Colombia, se ha referido expresamente al medio ambiente y los derechos humanos, reconociendo de manera expresa "la existencia de una relación innegable entre la protección del medio ambiente y la realización de otros derechos humanos, en tanto la degradación ambiental y los efectos adversos del cambio climático afectan el goce efectivo de los derechos humanos" (CIDH, 2017: 21-22). A esta interrelación entre la degradación ambiental y los derechos humanos a un ambiente sano y a la salud, la muestra de diferentes formas, particularmente haciendo referencia a las connotaciones individuales y colectivas del derecho a un medio ambiente sano por un lado; y distinguiendo entre derechos sustantivos y de procedimiento por otro lado.

En cuanto a la primera distinción entre derechos individuales y colectivos, expresa: "El derecho humano a un medio ambiente sano se ha entendido como un derecho con connotaciones tanto individuales como colectivas. En su dimensión colectiva, el derecho a un medio ambiente sano constituye un interés universal, que se debe tanto a las generaciones presentes y futuras. Ahora bien, el derecho al medio ambiente sano también tiene una dimensión individual, en la medida en que su vulneración puede tener repercusiones directas o indirectas sobre las personas debido a su conexidad con otros derechos, tales como el derecho a la salud, la integridad personal o la vida, entre otros. La degradación del medio ambiente puede causar daños irreparables en los seres humanos, por lo cual un medio ambiente sano es un derecho fundamental para la existencia de la humanidad." (CIDH, 2017: 27).

En otras palabras, la doctrina se refiere al daño ambiental como bicéfalo o bifronte, debido a que causa tanto daños colectivos como individuales. De esta manera, se diferencia entre el daño ambiental per se o de incidencia colectiva, que afecta a la calidad de vida de los distintos seres vivos y sus ecosistemas, a los bienes comunes; y el daño a los individuos a través del ambiente, donde encontramos los daños a la salud por ejemplo. En este sentido, "[...] el episodio de contaminación o de daño ambiental deja de ser un he- 
cho aislado, irrelevante, insignificante, o despreciable para el derecho, cuando repercute de rebote, o par ricochet, sobre la salud de un individuo, de una pluralidad de individuos, de un sector de la comunidad o de toda ella. Porque cuando el daño ambiental ataca el bien jurídico salud, desaparecen los límites de la normal tolerancia, o de las incomodidades ordinarias, del riesgo permitido, o del riesgo socialmente tolerable, para transformar el daño ambiental en una categoría de daño intolerable." (Cafferatta, 2011: 649).

En el decisorio de la Cámara Contencioso Administrativa que se comenta, respecto al bien común y el derecho a un ambiente sano, el Tribunal expresa:

“Entendemos que en una cuestión de la envergadura de la que nos ocupa no puede obviarse, bajo ningún aspecto, lo que significa la tutela del bien común. En el sub examine ello implica el derecho a un ambiente sano que tienen todos los habitantes de la Provincia de Córdoba; y no sólo los actores. De lo que se sigue que no está únicamente en juego el derecho de las personas cercanas al predio en cuestión, sino también el mismo derecho que tiene un colectivo mucho más extenso. En otros términos, el bien común trasciende al alcance que persiguen los actores. El bien común concierne a muchas más personas. Los que no están presentes en este juicio son el millón y medio de habitantes que residen en la ciudad de Córdoba o en lo que se denomina el Gran Córdoba. Ellos no tienen participación en la causa; pero su voz, sus necesidades, aunque silentes, no pueden ser obviadas por el Tribunal. Este aserto obliga a que la cuestión ambiental que nos ocupa no deba circunscribirse únicamente a las lesiones alegadas por los distintos actores a su derecho constitucional a un ambiente sano, sino también al derecho que tienen los habitantes del Gran Córdoba a gozar del mismo derecho." (Cam. Cont. Adm. $1^{\circ}$ Nom, 2019: 111-112).

Por otro lado, pensando en que además del reconocimiento al medio ambiente sano como derecho autónomo, los daños ambientales afectan a otros derechos humanos porque dependen de un medio propicio para su disfrute, la CIDH distingue entre derechos sustantivos y derechos de procedimiento. Los primeros son aquellos "cuyo disfrute es particularmente vulnerable a la degradación del medio ambiente", aquí encontramos el derecho a la vida, a la salud, a la integridad personal. Los derechos de procedimiento son aquellos cuyo ejercicio respalda una mejor formulación de políticas ambientales; entre los que se destaca el derecho a la información y la participación en cuestiones ambientales (CIDH, 2017: 29).

La Corte además destaca que "la salud constituye un estado de completo bienestar físico, mental y social, y no solamente la ausencia de afecciones o enfermedades. Por tanto, la contaminación ambiental puede causar afectaciones a la salud." (CIDH, 2017: 48). Estas afectaciones se ven de manera directa a través de algunos testimonios de habitantes de Bouwer, y de pericias socio-ambientales que se realizaron en un radio de $5 \mathrm{~km}$ en torno al ex enterramiento sanitario de Potrero del Estado 4 . Conforme surge de lo relatado en la Sentencia, los entrevistados coincidieron en que los impactos del enterramiento sanitario sobre la vida de la comunidad fueron negativos. Hicieron referencia a la invasión de olores nauseabundos, enfermedades gastrointestinales y dérmicas, la proliferación de moscas y roedores en cercanías al enterramiento, la contaminación de las napas de agua de las que se abastecían, entre otras cuestiones.

4 Estas incorporaciones a la causa se hicieron gracias a que los actores denunciaron que el EsIA no tuvo en cuenta los antecedentes de los impactos generados por los mega-enterramientos sanitarios sobre las poblaciones cercanas como la comunidad de Bouwer (Lacombe, 2020). 
Repasando algunas definiciones de salud y su correspondiente derecho, en íntima relación con el ambiente, Zalazar y Carranza exponen que, "se podría decir, como señaló en su tiempo René Dubós, que la salud es un estado físico y mental razonablemente libre de incomodidad y dolor, que permite a la persona en cuestión funcionar efectivamente por el más largo tiempo posible en el ambiente donde por elección está ubicado; o seguir a Alessandro Seppili, quien afirmaba que ésta era una condición de equilibrio funcional, tanto mental como físico, conducente a una integración dinámica del individuo en su ambiente natural y social" (Zalazar y Carranza, 2018:33).

Desde una perspectiva amplia, y como se adelantó en la introducción, el derecho a la salud es un derecho de incidencia colectiva y reviste un carácter bifronte -similar al daño ambiental-: por un lado se trata de un derecho personalísimo, que a su vez integra el derecho a la vida y a la dignidad de la persona; y por otro lado, es un derecho social, asumiendo el perfil de "derecho colectivo a la salud" (Cafferatta, 2011).

No queremos terminar este apartado sin hacer referencia brevemente al marco normativo constitucional del derecho a un ambiente sano, con énfasis en su relación con el derecho a la salud. En el año 1994, con la reforma constitucional, se incorporó en la Carta Magna el artículo 41 que reconoce de manera expresa, para todos los habitantes, el derecho a un medio ambiente sano, equilibrado y apto para todos los habitantes, y también su correlativo deber de preservación para las generaciones futuras. A partir de esta caracterización del ambiente, no cabe duda de la estrecha relación existente entre ambiente y salud en nuestra Constitución, de manera tal que hasta podría pensarse en el derecho al ambiente sano como una expresión del derecho a la salud (Cafferatta, 2011). Esta caracterización del ambiente como sano y equilibrado ha llevado a que desde la doctrina se discuta si este derecho a gozar de un ambiente sano protege al ambiente en sí mismo o protege a la salud humana en función del ambiente (Iglesias Rossini, 2016).

Es muy importante destacar, que además del artículo 41, con la reforma de 1994 se ha dado jerarquía constitucional a los Tratados de Derechos Humanos enumerados en el artículo 75 inciso 22, esto ensancha enormemente el marco normativo constitucional. Particularmente, el derecho humano al ambiente fue incorporado en importantes instrumentos jurídicos internacionales, ya sea de manera implícita como explícita. De manera implícita, en la Convención Americana sobre Derechos Humanos o Pacto de San José de Costa Rica se reconoce en el artículo 4 inciso $1^{\circ}$-Derecho a la vida-, y en el artículo 5 inciso $1^{\circ}$-Derecho a la integridad personal-, principalmente. Explícitamente, en el Protocolo Adicional a la Convención Americana sobre Derechos Humanos en materia de Derechos Económicos, Sociales y Culturales, conocido comúnmente como Protocolo de San Salvador de 1988, se establece el derecho de toda persona a vivir en un medio ambiente sano, y la obligación de los Estados de proteger, preservar y mejorar el medio ambiente (artículo 11). También reconoce de manera explícita el Derecho a la Salud, entendiéndola como "el disfrute del más alto nivel de bienestar físico, mental y social" (artículo 10).

Otro de los documentos internacionales que reconoce el derecho a vivir en un ambiente sano, en íntima relación con el derecho a la salud, es el Pacto Internacional de Derechos Económicos, Sociales y Culturales, que en su artículo 12 expresa: "1. Los Estados Partes en el presente Pacto reconocen el derecho de toda persona al disfrute del más alto nivel posible de salud física y mental. 2. Entre las medidas que deberán adoptar los Estados Partes en el Pacto a fin de asegurar la plena efectividad de este derecho, figurarán las 
necesarias para: [...]b) El mejoramiento en todos sus aspectos de la higiene del trabajo y del medio ambiente."

Por último, no se puede dejar de hacer referencia a la Conferencia de las Naciones Unidas sobre el Medio Ambiente y el Desarrollo, conocida como "Cumbre de la Tierra" o "Río 92", que se llevó a cabo en 1992 en Rio de Janeiro-Brasil, y tuvo como uno de sus resultados más importantes a la Declaración de Río sobre el Medio Ambiente y el Desarrollo, antecedente relevante del artículo 41 de nuestra Constitución Nacional. En su Principio 1 expresa que "Los seres humanos constituyen el centro de las preocupaciones relacionadas con el desarrollo sostenible. Tienen derecho a una vida saludable y productiva en armonía con la naturaleza." Aquí se presenta a la salud como adjetivo de la vida (Zalazar y Carranza, 2018), en un vínculo estrecho con la mirada antropológica del medio ambiente y el desarrollo sostenible. El Principio 14 también hace expresa referencia a la salud humana al indicar el deber de cooperación entre los Estados para desalentar o evitar actividades y sustancias que degraden en forma grave el ambiente o se consideren nocivas para la salud del hombre. Por último, el Principio 7 también se refiere a la cooperación entre los Estados, pero para conservar, proteger y restablecer la salud y la integridad del ecosistema de la Tierra. Aquí, la Declaración se corre del antropocentrismo de los demás artículos citados, y hace referencia a la salud desde una mirada ecosistémica.

\section{La participación ciudadana en el proceso de Evaluación de Impacto Ambiental: Licencia social y la lucha de los vecinos de Villa Parque Santa Ana}

En la Opinión consultiva citada anteriormente, la Corte hace referencia a la obligación de prevención y el principio precautorio en el marco de las obligaciones del Estado frente a posibles daños al medio ambiente, con el fin de respetar y garantizar los derechos a la vida, a la integridad personal y la salud. En otras palabras, la defensa del medio ambiente y la salud requiere de mecanismos anticipatorios de tutela a la luz de los principios de prevención y precautorios (Cafferatta, 2011).

Estos principios forman parte del derecho internacional ambiental, y si bien nacen en ese ámbito se expanden a otras ramas como el derecho de la salud. Aquí nos referiremos a la Ley General del Ambiente o Ley de Política Ambiental Nacional N²5675 (2002), y a la ley de política ambiental provincial $N^{\circ} 10208$ (2014) -que se incorpora al marco normativo de ley $\mathrm{N}^{\circ} 7343-$, porque son las de directa aplicación en el caso bajo estudio.

El artículo 4 de la Ley N²5675 y la Ley N¹0208 los define en los siguientes términos: “Principio de prevención: Las causas y las fuentes de los problemas ambientales se atenderán en forma prioritaria e integrada, tratando de prevenir los efectos negativos que sobre el ambiente se pueden producir.

Principio precautorio: Cuando haya peligro de daño grave e irreversible la ausencia de información o certeza científica no deberá utilizarse como razón para postergar la adopción de medidas eficaces, en función de los costos, para impedir la degradación del medio ambiente."

Los dos principios están estrechamente ligados por su objetivo que es evitar el daño ambiental -irreversible, grave, colectivo-. Sin embargo, existen diferencias ya que el principio preventivo actúa cuando existe certeza sobre los efectos de una actividad; mientras que el precautorio jugará cuando no haya certeza respecto de los efectos que producen 
determinadas actividades o productos, pero haya peligro de daño ambiental (grave e irreversible), lo que obliga a adoptar medidas de detención (Bestani de Saguir, 2011).

Entre los instrumentos que disponen los Estados para cumplir con ese deber preventivo y precautorio, se encuentra la EIA; reconocida en la Declaración de Río 92, leyes nacionales y provinciales.

Podemos conceptualizar a la EIA como "el análisis de las posibilidades de impacto ambiental que presenta un determinado proyecto o actividad que se pretende llevar adelante, a los fines de prevenir, de manera temprana, sus efectos ambientales perjudiciales y riesgosos y, de esta manera, permitir, modificar o impedir su concreción." (Falbo, 2011: 523).

La Ley $N^{\circ} 10208$, complementando la Ley N²5675, define la EIA como un "procedimiento técnico-administrativo realizado por la Autoridad de Aplicación, basado en el Estudio de Impacto Ambiental, dictamen técnico, estudios técnicos recabados y las opiniones y ponencia surgidas de las audiencias públicas u otros mecanismos de participación ciudadana implementados, que tiene por objetivo la identificación, predicción e interpretación de los impactos ambientales que determinadas políticas y/o proyectos públicos o privados pueden causar en la salud del hombre y/o en el ambiente, así como la prevención, corrección y valoración de los mismos, con el fin de aprobar o rechazar el Estudio de Impacto Ambiental." (artículo 17).

Continuando con la postura de la CIDH, los Estudios de Impacto Ambiental deben ser de carácter social y ambiental. "La inclusión de esos dos elementos en su caracterización, revela que el tipo de estudios exigidos por la Corte IDH debe ir más allá que los estudios del impacto estrictamente ambiental exigidos normalmente con miras a evaluar, prevenir y mitigar los posibles impactos negativos sobre el medio ambiente, haciendo necesario que se incorpore la identificación de los impactos directos o indirectos sobre las formas de vida y salud de los potenciales grupos sociales afectados." (Morales Lamberti, 2015: 84). En este sentido, lo "social" debe interpretarse desde una perspectiva amplia, incluyendo los impactos del proyecto en la dimensión económica, social, cultural, civil, política, la calidad de vida, la salud, el bienestar, etc, de la comunidad afectada (Morales Lamberti, 2015).

En este sentido, un informe realizado en el año 2017 por el Departamento de Antropología, avalado por el Consejo de la Facultad de Filosofía y Humanidades de la UNC; al evaluar el Estudio de Impacto Ambiental presentado por CORMECOR, señala:

“Un Estudio de Impacto Ambiental no sólo debe cumplir con la rigurosidad técnica suficiente para prever la aptitud de suelos, los riesgos de inundabilidad, la dispersión de contaminantes por aire, el riesgo de contaminación de napas; sino que esa misma rigurosidad y ética científica debe atender a los aspectos socio-ambientales. ¿Cómo este proyecto afectará la vida de las personas en el presente y en sus proyecciones futuras? ¿Cómo afectará su salud, su patrimonio, su identidad, sus proyectos?" (Posicionamiento FFyH, 2017: 5; en Lacombe, 2020:7).

Como adelantamos, otro de los ejes de la ratio decidendi de la sentencia, y que manifiestan los actores en sus demandas, es la valoración de la participación ciudadana ${ }^{5}$ en las

5 Como marco internacional debemos destacar el Principio 10 de la Declaración de Río de 1992 que se refiere a los derechos de acceso a la información, a la participación y a la justicia ambiental; y el reciente Acuerdo Regional sobre Acceso a la Información, la Participación Pública y el Acceso a la Justicia en Asuntos 
audiencias públicas. En consonancia con los lineamientos generales establecidos por la Ley General del Ambiente $N^{\circ} 25675$ en materia de participación ciudadana (artículos 19 a 21), la ley provincial $N^{\circ} 10208$ dispone que "todos los ciudadanos tienen derecho a participar y opinar acerca de las acciones, obras o actividades que se desarrollen en el territorio de la Provincia y puedan afectar el ambiente, sus elementos o la calidad de vida de la población" (artículo 63). Además, establece que este proceso es parte integrante de todo procedimiento administrativo de EIA; que es promovido y conducido por la Autoridad de Aplicación con la participación del proponente y de los actores sociales que están alcanzados por los impactos positivos y/o negativos del proyecto; y que su realización tendrá carácter obligatorio y deberá realizarse previo al otorgamiento o rechazo de la Licencia Ambiental (artículos 13 y 64). En tal sentido, el artículo 29 dispone que una vez verificado por parte de la Autoridad de Aplicación el cumplimiento de las condiciones establecidas por ley para tal proceso y valoradas "las opiniones, ponencias, informes técnicos y científicos que surjan del proceso de participación ciudadana", deberá otorgar o denegar la Licencia ambiental correspondiente. Para el análisis del caso "Complejo ambiental" es indispensable tener presente el artículo 29 infine que expresa: "La opinión u objeción de los participantes no será vinculante para la Autoridad de Aplicación, pero en caso de que ésta presente opinión contraria a los resultados alcanzados en la audiencia o consulta pública, debe exponer fundadamente los motivos de su apartamiento y hacerlo público".

En palabras de la CIDH en la Opinión Consultiva: "La participación representa uno de los pilares fundamentales de los derechos instrumentales o de procedimiento, dado que es por medio de la participación que las personas ejercen el control democrático de las gestiones estatales y así pueden cuestionar, indagar y considerar el cumplimiento de las funciones públicas. En ese sentido, la participación permite a las personas formar parte del proceso de toma de decisiones y que sus opiniones sean escuchadas. En particular, la participación pública facilita que las comunidades exijan responsabilidades de las autoridades públicas para la adopción de decisiones y, a la vez, mejora la eficiencia y credibilidad de los procesos gubernamentales." (CIDH, 2017:91).

Lo anterior queda plasmado en la Sentencia analizada al expresar: "[...] la falta de exposición en la Resolución N¹0/2017 de los motivos del apartamiento de la opinión y objeciones de los participantes de la Audiencia Púbica constituye una omisión que, aunada a otros elementos que surgen de la presente causa, importa invisibilizar a los afectados directos por el emprendimiento Complejo Ambiental" (Cam. Cont. Adm. 1Nom, 2019: 190).

El Tribunal continua: “No sólo ha quedado acreditada la falta de respuesta a los planteos y objeciones realizadas por el Municipio de Villa Parque Santa Ana y los asistentes a la Audiencia Pública; sino también la falta de respuesta a los planteos del Sr. Intendente de esa localidad, la ausencia de adopción de las medidas informativas y de difusión que habían sido recomendadas - recuérdese que el Estudio de Geoambiental había señalado que el $92 \%$ de los habitantes de VPSA no conocía los alcances del proyecto-. Además, tampoco puede perderse de vista que el Municipio de Villa Parque Santa Ana no integra Cormecor S.A. (estando emplazada geográficamente en la zona de influencia directa del proyecto); y, el contraste de la profundidad de los estudios y relevamientos socio-ambientales realizados por el ISEA para las localidades de Juárez Celman y Bower, localidades próximas a los sitios donde estaba previsto el emplazamiento original del proyecto, y

Ambientales en América Latina y el Caribe, adoptado en Escazú, Costa Rica, en 2018; y que se encuentra actualmente sujeto a ratificación. 
los relevamientos realizados por Geoambiental para Villa Parque Santa Ana, reiteramos, la localidad más cercana al emprendimiento." (Cam. Cont. Adm. 1Nom, 2019: 261).

A la Evaluación de Impacto Ambiental, cabe agregar otros instrumentos que se incorporaron en los últimos años en el marco normativo provincial (Ley $N^{\circ} 10208$ ), como la Evaluación Ambiental Estratégica (Capítulo Vl) y, especialmente, la regulación de acciones de salud ambiental (Capítulo XV); reconociéndose de esta manera la necesidad de avanzar en la prevención de actividades que puedan tener efectos en la salud de las personas. Respecto a este último capítulo, las acciones en salud ambiental están destinadas a que los ministerios a cargo de las temáticas de salud y de ambiente promuevan "acciones de salud ambiental destinadas a asegurar el mejoramiento de la calidad de vida de las generaciones presentes y futuras en forma prioritaria" (artículo 83).

Las acciones de salud ambiental se expresan en dos tipos de instrumentos: por una parte, a través de los planes quinquenales de salud ambiental, y por otra parte, en la Evaluación de Impacto en Salud (en adelante EIS) (Juliá, 2019).

La ley establece cuando y para qué se utiliza la EIS, determinando tres tipos de posibilidades para usar este instrumento: a) en el procedimiento de Evaluación de Impacto Ambiental se solicita de forma complementaria para aquellas actividades que pudieran generar efectos negativos significativos sobre la salud, b) en los proyectos que no son sometidos a Evaluación de Impacto Ambiental a pedido de la autoridad de aplicación cuando lo considere necesario, y c) en proyectos y/o actividades en curso anteriores a la aprobación de la ley y que generen conflictividad social por producir efectos negativos sobre la salud (Juliá, 2019).

Otro de los instrumentos de política y gestión ambiental estrechamente vinculado con la gestión de los RSU, particularmente con la localización de las plantas de disposición final, es el Ordenamiento Ambiental del Territorio (en adelante OAT) (Novak, 2019). Se encuentra receptado en la Ley nacional $\mathrm{N}^{\circ} 25675$ en los artículos 9 y 10, y debidamente complementada por la Ley $\mathrm{N}^{\circ} 10208$ de la provincia de Córdoba. Esta última, dispone en su artículo 9: “[...] En el proceso de Ordenamiento Ambiental del Territorio se tendrán en cuenta los aspectos políticos, físicos, sociales, tecnológicos, culturales, económicos, jurídicos y ecológicos de la realidad local, regional y nacional.

El Ordenamiento Ambiental del Territorio debe asegurar el uso adecuado de los recursos ambientales, posibilitar la producción armónica y la utilización de los diferentes ecosistemas, garantizar la mínima degradación y desaprovechamiento y promover la participación social en las decisiones fundamentales del desarrollo sustentable."

\section{Gestión y disposición final de los residuos sólidos urbanos}

Muchos identifican el término basura con el de residuo, pero hay diferencias. Mientras que la basura se asocia a lo que ya no sirve, es inútil o no tiene valor para la sociedad; se denomina residuo a lo que sí puede reaprovecharse o es susceptible de ser transformado en un nuevo producto (Schejtman e Irurita, 2012). La cantidad de residuos ha aumentado considerablemente en las últimas décadas, como consecuencia directa del modelo de producción y consumo de la modernidad y su cultura del descarte. Este incremento ocasiona que gestionar los RSU se convierta en un problema para la mayoría de las ciudades, a lo que no escapa Córdoba y su área metropolitana. 
Esta gestión de los RSU o residuos domiciliarios que, como dijimos, es uno de los grandes desafíos de la política pública municipal, impacta de manera directa en la calidad de vida de las personas. No sólo incluye al Estado como prestador del servicio público de recolección de residuos; sino que interpela a los ciudadanos como generadores de RSU en sus actividades cotidianas (Novak, 2019). La realidad nos muestra que no existe un abordaje integral del sistema de residuos que comprenda su ciclo completo -desde la generación hasta la disposición final (y más aún: la reinserción en el mercado de los materiales recuperados)-, sino que hay soluciones parciales y provisorias; ya sea por falta de recursos financieros, falta de coordinación interjurisdiccional, escasez de conocimientos y personal capacitado, etc (Schejtman e Irurita, 2012).

Lo expresado se evidencia también en la sentencia, al decir:

“[...]Esto es especialmente relevante en la gestión de la basura, que no es más que el desecho de la sociedad, que crece exponencialmente, motorizada por un consumo irresponsable y corto de miras. En general, en el actual sistema económico, la producción de basura es inevitable y, en el mejor de los casos, lo que se busca es reutilizar parte de ella para volver a introducirla en el circuito productivo. Esta última estrategia es sólo posible, [...] a través de un profundo cambio cultural, que involucra no solo al Estado sino también, esencialmente, a la población. Por lo tanto, tal modificación debe ser precedida inevitablemente por un radical cambio educativo que abarque a todos los estratos sociales." (Cam. Cont. Adm. $1^{\circ}$ Nom, 2019: 112).

Respecto al marco normativo, en el ámbito internacional, entre los instrumentos que se firmaron en la Conferencia de Río 92, se encuentra el Plan de Acción denominado Agenda 21. En el Capítulo 21 titulado: Gestión Ecológicamente Racional de los Desechos Sólidos y cuestiones relacionadas con las Aguas Cloacales, expresa: “La gestión ecológicamente racional de los desechos debe ir más allá de la simple eliminación o el aprovechamiento por métodos seguros de los desechos producidos y procurar resolver la causa fundamental del problema intentando cambiar las pautas no sostenibles de producción y consumo. Ello entraña la aplicación del concepto de gestión integrada del ciclo vital que representa una oportunidad única de conciliar el desarrollo con la protección del medio ambiente."

A nivel nacional ${ }^{6}$, específicamente en materia de RSU, en el año 2004 se sancionó la Ley №25916 de Presupuestos Mínimos para la Gestión Integral de Residuos Domiciliarios; complementada a nivel provincial por la Ley N9088. En el artículo 2 define al residuo domiciliario como "aquellos elementos, objetos o sustancias que como consecuencia de los procesos de consumo y desarrollo de actividades humanas, son desechados y/o abandonados". Lo más significativo es que se refiere a la gestión integral de los residuos definiéndola como "conjunto de actividades interdependientes y complementarias entre sí, que conforman un proceso de acciones para el manejo de residuos domiciliarios, con el objeto de proteger el ambiente y la calidad de vida de la población." (artículo 3). Esta gestión integral comprende las etapas de generación, disposición inicial, recolección, transferencia, transporte, tratamiento y disposición final.

Por el caso que nos ocupa en esta nota, haremos especial hincapié en la etapa de disposición final que comprende el conjunto de operaciones que tienen por objetivo lograr el

6 A nivel provincial la ley específica es la Nº088 de "Gestión de Residuos Sólidos Urbanos (RSU) y residuos asimilables a los (RSU)", a nivel municipal rige la Ordenanza $\mathrm{N}^{\circ} 12.648 / 17$ como Marco Regulatorio para la gestión integral de residuos sólidos urbanos. Ambas normativas se enmarcan y complementan la Ley de Presupuestos Mínimos º25916 conforme al tercer párrafo del artículo 41 de la Constitución Nacional. 
depósito permanente de los RSU. El método más comúnmente utilizado a nivel mundial es la disposición en tierra, el enterramiento. Los centros de disposición final son definidos por la Ley N²5916 como "aquellos lugares especialmente acondicionados y habilitados por la autoridad competente para la disposición permanente de los residuos" (artículo 17). Se explaya respecto a las condiciones de su ubicación en los artículos 20 y 21 : “Artículo 20: Los centros de disposición final deberán ubicarse en sitios suficientemente alejados de áreas urbanas, de manera tal de no afectar la calidad de vida de la población; y su emplazamiento deberá determinarse considerando la planificación territorial, el uso del suelo y la expansión urbana durante un lapso que incluya el período de postclausura. Asimismo, no podrán establecerse dentro de áreas protegidas o sitios que contengan elementos significativos del patrimonio natural y cultural.

Artículo 21: Los centros de disposición final deberán ubicarse en sitios que no sean inundables. De no ser ello posible, deberán diseñarse de modo tal de evitar su inundación."

La ubicación del enterramiento plantea conflictos significativos, como el que aquí tratamos, por varios motivos: la magnitud del espacio necesario y la afectación del hábitat de la zona circundante a dichas instalaciones, entre los principales (Novak, 2019). Esta afectación, bajo una mala gestión, representa un peligro como fuente de contaminación del suelo, el aire y el agua; además de la posibilidad de ser, un foco infeccioso para las poblaciones cercanas (Schejtman e Irurita, 2012).

A esto se refiere el Tribunal en la Sentencia:

"Toda esta falta de conciencia, desidia y hasta ignorancia ambiental hace que haya más basura; y mientras más gente viva en un conglomerado urbano, más basura se produce. Al crecer tal conglomerado, la basura se tiene que ubicar cada vez más lejos de sus productores porque, aunque son quienes lo han generado, no la quieren ver, no la quieren sentir, no la quieren oler, no la quieren padecer.

Esa es la razón por la cual estamos en juicio. Los habitantes de la ciudad de Córdoba y lo que ya se está constituyendo en "Gran Córdoba", más allá de la responsabilidad que tienen en la producción de la basura, necesitan alejarla de ellos. Necesitan disponer de la misma de modo tal que no interfiera en su vida diaria. No está en discusión que la basura debe tener un destino adecuado. Lo que ocurre es que nadie la quiere cerca, por múltiples razones. Éste no es un fenómeno nuevo. Tanto es así que se ha acuñado un acrónimo para el mismo: "NINBY" ("Not in my back yard"), que traducido significa "No en mi patio trasero" (Cam. Cont. Adm. 1Nom, 2019: 112-113).

\section{Y determina:}

"La solución de compromiso, ambientalmente viable, es que la radicación del Complejo Ambiental se haga en un sitio lo suficientemente alejado de donde los directamente afectados viven y desarrollan sus actividades, y/o que la planta cuente con la tecnología y diseño acordes a la distancia que la separa de las personas, justamente para que éstas no sean afectadas, o lo sean mínimamente." (Cam. Cont. Adm. 1Nom, 2019: 114).

Comúnmente, se entiende como efecto o síndrome NIMBY a la resistencia de grupos locales al emplazamiento en sus territorios de "equipamientos, infraestructuras o servicios que presuponen algún tipo de riesgo" (Lacombe, 2020: 13). Desde esa perspectiva se considera a esas reacciones como expresiones individualistas y egoístas, que se oponen 
a los cambios obstaculizando de esta forma el desarrollo, "ya que estos grupos no ponderan más que los costos locales y no los beneficios globales de los emprendimientos o infraestructuras en cuestión" (Lacombre, 2020: 13).

Lacombe, antropóloga, que se desempeñó como perito de parte de los vecinos de ViIla Parque Santa Ana, critica la Teoría NIMBY. Expone que esa perspectiva teórica no cuestiona los daños generados por el "progreso" al ambiente, ni revisa alternativas a los modos imperantes de producción, consumo y descarte; que podrían minimizar y hasta evitar esos daños. No visibiliza las injusticas ambientales y desconoce los movimientos sociambientales al reducirlos a acciones no solidarias que se oponen al progreso. En palabras de Lacombe, "en esta perspectiva teórica subyace una visión conservadora del progreso; ya que no admite críticas ni transformaciones a los modos en que el desarrollo industrial y extractivista está afectando las vidas de las comunidades, los territorios y la sustentabilidad de las generaciones futuras. Es una perspectiva que concibe a las demandas ciudadanas como una amenaza; desacredita la participación ciudadana en la toma de decisiones que afectan su ambiente, justifica el sacrificio de minorías en post del beneficio de supuestas mayorías... Por lo cual esta teoría discrepa con cualquier perspectiva de derechos humanos universales, de igualdad ante la ley y de derecho ambiental" (Lacombe, 2020: 13-14).

\section{Reflexiones finales}

“¿El planeta? Úselo y tírelo. En el reino de lo efímero, todo se convierte inmediatamente en chatarra." (Galeano, 2014 : 175)

Este trabajo tuvo por objetivo destacar y analizar los ejes del fallo en los autos caratulados: “Complejo Ambiental de Tratamiento, Valoración y Disposición Final de Residuos Sólidos Urbanos de Córdoba y otros - Cuestión Ambiental" del 30 de diciembre de 2019; que trata sobre el conflicto suscitado a raíz de la instalación de una planta de tratamiento de RSU en un predio ubicado en cercanías de Villa Parque Santa Ana, a 15km al suroeste de la ciudad de Córdoba. Los puntos entorno a los cuales gira el decisorio son: la ubicación del predio elegido para la disposición final de los RSU de varios municipios, la falta de información y participación de la ciudadanía en el proceso de EIA y las cuestiones sociales que deben ser ponderadas en dicha evaluación.

El recorrido de este comentario tiene como columna vertebral el vínculo entre los derechos humanos a un ambiente sano y a la salud; ambos afectados directamente por los RSU, particularmente por una gestión deficiente en su disposición final. Tanto la sentencia como el marco normativo reconstruido en este trabajo, muestran como común denominador el concepto "calidad de vida", y cómo el mismo se ve afectado por los daños ambientales en general, y particularmente, los referidos a la gestión de la disposición final de los desechos.

También, se ha repasado el marco normativo y la importancia de la participación de la ciudadanía informada en los procesos de decisión sobre cuestiones ambientales, cuestiones de índole colectiva. La sentencia analizada reafirma la importancia de la participación, no dejando pasar por alto la falta de fundamentación ante una decisión contraria a lo que surge de la audiencia pública en la EIA. Reconoce de esta manera, el valor de una ciudadanía consciente, activa y comprometida con la defensa de sus derechos fundamentales. 
Es indispensable destacar la importancia fundamental de una gestión integral de los RSU, desde su generación hasta su disposición final y posible reutilización (economía circular). Debe tratarse de un ciclo, donde se tomen medidas que aborden el problema en forma completa; dando solución a esta problemática social, ambiental, política, económica que enfrenta la sociedad en general y los municipios en particular. Estas decisiones implican mayor financiamiento, revisión normativa respecto a los instrumentos de gestión, innovación tecnológica, coordinación interjurisdiccional, formación y capacitación a los funcionarios y decisores, llevar adelante campañas de sensibilización/concientización ambiental para impactar en la disposición inicial de los RSU, entre otras cuestiones.

Pero, más allá de lo anterior, si pensamos concretamente en las causas profundas de esta situación crítica de los "basurales", debemos replantearnos los modelos de producción y consumo imperantes, donde el descarte es la primer -y única- opción. Esto finalmente, debe ser lo prioritario a la hora de gestionar los residuos, ya que la mayoría de ellos pueden ser minimizados si modificamos nuestros hábitos en su generación. Continuar discutiendo dónde enterrar la basura es insustentable!

Por último, cabe agregar que, ya se admitieron recursos de apelación frente a este fallo; ahora debe resolver el Tribunal Superior de Justicia de la Provincia de Córdoba.

\section{REFERENCIAS BIBLIOGRÁFICAS}

- Bestani de Saguir, A. (2011). El principio de precaución en el derecho ambiental. En Cafferatta, N. (dir.). Summa Ambiental. Doctrina-Legislación-Jurisprudencia (pp. 641-655). Buenos Aires: Abeledo Perrot.

- Cafferatta, N. (2011). Derecho a la salud y derecho ambiental. En Cafferatta, N. (dir.). Summa Ambiental. Doctrina-Legislación-Jurisprudencia (pp. 641-655). Buenos Aires: Abeledo Perrot.

- Cámara Contencioso Administrativa 1ra Nominación (2019). En autos: “Complejo Ambiental de Tratamiento, valoración y disposición final de residuos sólidos urbanos de Córdoba y otros - Cuestión ambiental" (Expte. N 6351888). Disponible en: https://www. justiciacordoba.gob.ar/justiciacordoba/inicio/indexDetalle.aspx?codNovedad=21998

- Corte Interamericana De Derechos Humanos (2017). Opinión consultiva: Medio ambiente y Derechos Humanos (OC-23/17). Disponible en: http://www.corteidh.or.cr/docs/ opiniones/seriea_23_esp.pdf.

- Falbo, A. (2011). Evaluación de impacto ambiental: su concepto y caracteres. En Cafferatta, N. (dir.). Summa Ambiental. Doctrina-Legislación-Jurisprudencia (pp. 641-655). Buenos Aires: Abeledo Perrot.

- Galeano. E. (2014). Úselo y tírelo. El mundo visto desde una ecología latinoamericana. Buenos Aires: Booket.

- Iglesias Rossini, G. (2016). El derecho a gozar de un ambiente sano: Relaciones entre la salud y el Ambiente. Revista de la Facultad de Derecho, 40, 159-176. Disponible en: http:// www.scielo.edu.uy/scielo.php?pid=S2301-06652016000100007\&script=sci_abstract

- Juliá, M. (2019). La regulación de acciones en salud ambiental en la provincia de Córdoba. Diario Administrativo, 265, s/d. 
- Lacombe, E. (2020). "No al basural": Un fallo a favor de los vecinos. Alfilo. Disponible en: https://ffyh.unc.edu.ar/alfilo/no-al-basural-un-fallo-a-favor-de-los-vecinos/

- Morales Lamberti, A. (2015). Evaluación de impacto ambiental y social: estándares sustantivos y de procedimiento en el Sistema Interamericano de Derechos Humanos. En Drnas de Clément, Z.(dir.). Cuaderno de Derecho Ambiental. Evaluación de Impacto Ambiental (pp. 69-108). Córdoba: Advocatus.

- Novak, A. (2019). Residuos Sólidos Urbanos, un problema de todos. Actualidad Jurídica, $288, \mathrm{~s} / \mathrm{d}$.

- Pascual, A. et al. (2010). Los residuos sólidos urbanos y su relación con la salud. En Barragán, H. (ed.). Desarrollo, salud humana y amenazas ambientales. La crisis de la sustentabilidad (pp. 217-228). La Plata: Universidad Nacional de La Plata.

- Shejtman, L. e Irurita, N. (2012). Diagnóstico sobre la gestión de los residuos sólidos urbanos en municipios de la Argentina. Documento de trabajo n¹03 CIPPEC. Disponible en: https://www.cippec.org/wp-content/uploads/2017/03/1552.pdf

- Zalazar, C. y Carranza, G. (2018). Aproximación sistémica al concepto de derecho a la salud. O movimento entre os saberes. Direito à Saúde na Sociedade em Rede, V. X, 29-49. 